\title{
Anxiety disorders in children with Williams syndrome, their mothers, and their siblings: Implications for the etiology of anxiety disorders
}

\author{
Ovsanna Leyfer • Janet Woodruff-Borden • \\ Carolyn B. Mervis
}

Received: 11 March 2008 / Accepted: 21 January 2009 /Published online: 13 February 2009

(C) Springer Science + Business Media, LLC 2009

\begin{abstract}
This study examines the prevalence of anxiety disorders in children with Williams syndrome (WS), their sibling closest in age, and their mothers as well as the predictors of anxiety in these groups. The prevalence of anxiety disorders was assessed and compared to that in the general population. Children with WS had a significantly higher prevalence of specific phobia, generalized anxiety disorder (GAD), and separation anxiety in comparison to children in the general population. While mothers had a higher prevalence of GAD than population controls, the excess was accounted for by mothers who had onset after the birth of their WS child. The siblings had rates similar to the general population. This pattern of findings suggests the presence of a gene in the WS region whose deletion predisposes to anxiety disorders. It is also worthwhile to investigate relations between genes deleted in WS and genes previously implicated in anxiety disorders.
\end{abstract}

Keywords Genetics · Anxiety · Family - Mental retardation . Intellectual disability $\cdot$ Williams syndrome

Anxiety disorders are among the most common psychiatric disorders, with a lifetime prevalence of approximately $25 \%$ in adults [1] and $4-9 \%$ in children [2, 3]. Moreover, many adult anxiety disorders have their onset in childhood or

\section{O. Leyfer $(\bowtie)$}

Center for Anxiety and Related Disorders, Boston University, 648 Beacon Street, 6th Floor,

Boston, MA, USA

e-mail: oleyfer@bu.edu

J. Woodruff-Borden · C. B. Mervis

Department of Psychological and Brain Sciences,

University of Louisville,

Louisville, KY 40292, USA adolescence and may have a chronic course [e.g., 4, 5]. They are also highly co-morbid with each other and other psychiatric disorders, especially with mood disorders [e.g., 6] and are associated with high levels of occupational and social impairment [e.g., 7].

The Diagnostic and Statistical Manual of Psychiatric Disorders (DSM-IV-TR) [8] specifies the following types of anxiety disorders in children and adults: separation anxiety, panic disorder (PD), agoraphobia, specific phobia, social phobia, generalized anxiety disorder (GAD), obsessivecompulsive disorder (OCD), post-traumatic stress disorder (PTSD), and acute stress disorder (Table 1).

Given their high prevalence and the accompanying impairment, the etiology of anxiety disorders is of major interest and importance. It has been investigated through a number of genetic approaches, including family studies, which provide information about the familial aggregation of the disorder [9]; twin studies, which investigate heritability of the disorder by comparing the concordance rate for a specific condition in pairs of monozygotic (MZ) and dizygotic (DZ) twins [9]; and association and linkage studies, which seek to identify specific genes or chromosomal regions related to anxiety disorders [10].

Family studies of anxiety disorders [11-13] have demonstrated familiality of specific anxiety disorders. Familial aggregation of anxiety disorders in general has been demonstrated as well. For example, Merikangas and colleagues [14-16] found that the risk of developing an anxiety disorder in children aged 7-17 years was three times as high if a parent had an anxiety disorder as if a parent had a substance abuse disorder or neither parent had a psychiatric diagnosis. Turner, Bidel, and Costello [17] found that children of parents with anxiety disorders were seven times more likely to develop an anxiety disorder than children of control parents without a psychiatric diagnosis. 
Table 1 Diagnostic features of the DSM-IV-TR anxiety disorders

\begin{tabular}{ll}
\hline Disorder & Key diagnostic features \\
\hline $\begin{array}{l}\text { Separation anxiety } \\
\text { Panic disorder }\end{array}$ & $\begin{array}{l}\text { Excessive anxiety associated with separation from home or caregivers } \\
\text { Panic attacks and persistent concern about the future recurrence of attacks as well as } \\
\text { worry about the consequences of the panic } \\
\text { Excessive fear of specific objects or situations, subsequent avoidance of those, } \\
\text { and/or distress associated with exposure to these objects or situations }\end{array}$ \\
Excessive fear of social and performance situations and subsequent avoidance \\
of and/or distress associated with exposure to the situation
\end{tabular}

Several twin studies of specific anxiety disorders have been conducted [18-21]. In most studies the concordance rates were higher for $\mathrm{MZ}$ twins than for $\mathrm{DZ}$ twins. Hettema et al. [22], in a meta-analysis of twin studies of anxiety disorders, estimated $30-40 \%$ heritability for anxiety disorders, depending on the disorder.

Multiple molecular genetic studies of anxiety disorders have been conducted as well, including linkage and association studies. Although several candidate chromosomal regions, genes, and polymorphisms have been linked to anxiety disorders [reviewed in 10], many of the initial findings are conflicting, and no specific genes have been identified thus far. This is not surprising; although anxiety disorders aggregate in families, their mode of inheritance does not follow a clear Mendelian pattern (i.e., dominant, recessive, or X-linked). Instead, these are complex disorders that appear to be caused by an interaction among a variety of genes as well as environmental factors [23]. Additionally, because the pathophysiology of anxiety disorders remains unclear, choosing candidate genes for association studies is not easy.

A number of chromosomal and genetic disorders caused by deletions, trisomies, or translocations are associated with specific behavioral characteristics, referred to as behavioral phenotypes [24]. Although these behavioral characteristics may include psychiatric features, the complete profiles of psychiatric features and their risk factors in these disorders are unknown. Examination of genetic neurodevelopmental disorders associated with high prevalence rates of a particular psychiatric disorder may provide a complementary approach in the search for susceptibility genes for complex disorders [25]. Association studies can be conducted using the genetic markers on the locus or the genes implicated in the chromosomal abnormality. Also, hypotheses may be made about the interaction of the chromosomal region involved in the abnormality and genes that have already been implicated in these disorders in previous studies.

Karayiorgou and Gogos [26] state that to determine reliably a causal relation between a chromosomal abnormality and a disease, one or preferably both of the following criteria must be demonstrated: 1) increased frequency of the disease in a population with the chromosomal abnormality and 2) increased frequency of the chromosomal abnormality in the population with the disease. Studies of complex disorders such as schizophrenia and Alzheimer disorder [e.g., 25, 27, 28] have demonstrated the success of this approach. For example, findings of elevated prevalence of schizophrenia in individuals with 22q11 deletion syndrome have prompted genetic linkage and association studies of schizophrenia on chromosome $22 q$, which have led to finding a potential schizophrenia susceptibility locus on chromosome 22q [reviewed in 25]. Similar strategies can be applied to genetic studies of anxiety disorders.

Williams syndrome (WS) is a neurodevelopmental disorder caused by a microdeletion of $\sim 25$ genes on chromosome $7 q 11.23$ [29, 30]. It is associated with mild to moderate intellectual disability or learning difficulties, a characteristic facies, heart disease (especially supravalvar aortic stenosis), hypercalcemia, and failure to thrive in infancy [31]. The cognitive phenotype for WS includes relative strengths in verbal short-term memory and language and extreme weakness in visuospatial construction, including writing, drawing, and pattern construction [e.g., 32]. A number of studies have considered the behavioral and emotional characteristics of individuals with WS [33-41], identifying such characteristics as anxiety, restlessness, and mood swings. However, most of these reports did not assess for DSM-IV diagnoses of anxiety disorders.

Leyfer, Woodruff-Borden, Klein-Tasman, Fricke, and Mervis [42] examined the prevalence of psychiatric 
disorders in 119 children with WS aged 4-16 years, using the Anxiety Disorders Interview Schedule, Parent version (ADIS-P) [43], a semi-structured diagnostic interview, which allows for making differential diagnoses among the $D S M-I V$ anxiety and mood disorders. The results demonstrated prevalence rates of $54 \%$ for specific phobia, $12 \%$ for generalized anxiety disorder (GAD), 7\% for separation anxiety disorder, $3 \%$ for obsessive-compulsive disorder (OCD), $2 \%$ for social phobia, $1 \%$ for post traumatic stress disorder (PTSD), and $1 \%$ for panic disorder.

In summary, the preliminary evidence suggests that anxiety disorders are found at higher prevalence in individuals with WS, and hence WS may be used to search for genes implicated in anxiety disorders. However, the causes of anxiety in individuals with WS are unclear. Systematic studies of anxiety disorders in individuals with WS and their first-degree relatives will shed light on the possible relations between family history of anxiety and anxiety disorders in individuals with WS and open the door for further studies of pathophysiology of anxiety. The purpose of this paper is to provide the first such study.

No studies have examined the prevalence of anxiety disorders in family members of individuals with WS. Studies of anxiety in the first degree relatives of children with other forms of developmental disability (DD) [44-48] do not clearly demonstrate whether parents of children with DD have elevated anxiety in comparison to the general population. However, it is possible that anxiety levels among parents of children with DD may vary depending on the child's behaviors, level of functioning, and other such variables. Such relations have been reported for parenting stress. For example, Weiss, Sullivan, and Diamond [49] demonstrated that lower adaptive functioning scores in children with DD predict higher levels of parental stress. Emerson [50] found that the following factors related to having a child with DD contributed to the prevalence of mental health problems in the mothers: if the child with DD is a male, poverty, and the parent's perception of the social impact of the child's difficulties.

Fidler, Hodapp, and Dykens [51] examined which child variables may affect the levels of stress in families of 20 children with WS, Down syndrome (DS), and Smith-Magenis syndrome. Results indicated that for the parents of the children with WS, younger age of the child and maladaptive behavior as measured by the CBCL Total Problems T score [52] accounted for $59 \%$ of the variance in family stress. These findings suggest that child variables such as adaptive functioning and behavioral problems may be predictive of anxiety in parents of children with WS. Demographic factors such as employment, child age, and child gender may also predict anxiety in parents of children with WS.

A few studies of siblings of children with other forms of DD have been conducted, with contradictory results.
McHale and Gamble [53] reported a significantly higher anxiety score for siblings of children with intellectual disability (ID) than for the controls on the Revised Children's Manifest Anxiety Scale (RCMAS) [54]. In contrast, using the same measure, Coleby [55] did not find a difference in the anxiety score between the two groups of siblings.

In summary, very few studies have investigated anxiety in parents and siblings of children with DD. The purpose of the current study was to determine the prevalence of anxiety disorders in children with WS, their sibling closest in age, and their mothers and to examine the predictors of anxiety in these groups, to help determine if hemideletion of one or more genes in the WS region is likely to contribute to anxiety disorders.

\section{Method}

Participants

The participants were recruited through a study of language and cognitive development in children with WS conducted by Drs. Carolyn Mervis and Colleen Morris at the University of Louisville and the University of Nevada School of Medicine. The University of Louisville site primarily focuses on cognitive and language development, while the University of Nevada site focuses on genetic and medical aspects of WS. Participants eligible for the study included mothers who had biological children between the ages of 4-16 years with genetically-confirmed WS. The majority of the families also had another child in the same age range (half-siblings were included if they had the same mother). Exclusionary criteria for the participants were: 1) the presence of another genetic or developmental disorder in the child with WS $(n=11$; in all cases autism or pervasive developmental disorder, not otherwise specified), 2) the presence of organic brain damage in the child with WS $(n=2)$, and 3$)$ the presence of a developmental disorder or organic brain damage in the mother or the sibling of the child with WS $(n=1)$. The characteristics of the sample are presented in Table 2.

\section{Measures}

Anxiety Disorders Interview Schedule-IV (ADIS-IV) [56] Maternal diagnostic status was obtained with the ADIS-IV, a semi-structured diagnostic interview that allows for differential diagnoses of DSM-IV anxiety and related disorders in adults. The ADIS-IV provides information both about specific anxiety disorder diagnoses and their severity [rated on a scale from 0 (no anxiety) to 8 (very severe anxiety)].

Although no psychometric data are available for the ADIS-IV, the ADIS-IV: Lifetime Version (ADIS-IV-L) has been reported to have good to excellent reliability (kappas 
Table 2 Demographic information

${ }^{1}$ No difference found in income between families with employed and unemployed mothers $(p=.772)$.

Note. DAS GCA $=$ Differential Ability Scales General Conceptual Ability score; $\mathrm{M}(\mathrm{SD})=$ Mean (standard deviation);

SIB-R Broad Ind = Scales of Independent behavior-Revised Broad independence score.

\begin{tabular}{llll}
\hline & Children with WS & Siblings & Mothers \\
\hline$N$ & 132 & 84 & 132 \\
Age M (SD), Range & $8.5(3.3), 4.0-16.9$ & $9.7(3.1), 4.2-16.6$ & $38.7(5.9), 22.7-58.2$ \\
Sex $N(\%)$ & $63(47.7 \%)$ & $44(52.4 \%)$ & \\
Males & $60(52.3 \%)$ & $40(47.6 \%)$ & \\
Females & $60.2(13.6),<25-94$ & & \\
DAS GCA M (SD), Range & & & \\
SIB-R Broad Ind. & $55.9(14.3), 15-95$ & & $113(86 \%)$ \\
M (SD), Range & & $15(11 \%)$ \\
Marital status $N(\%)$ & & $4(3 \%)$ \\
Married & & & $16(12 \%)$ \\
Divorced & & $26(20 \%)$ \\
Single & & $45(34 \%)$ \\
Income $N(\%)$ & & $45(34 \%)$ \\
$<\$ 30,000$ & & \\
\$21-60,000 & & $N=72(54.5 \%)$ \\
\$61-90,000 & & $N=40(45.5 \%)$ \\
E 91,000 & & \\
Employment $N(\%))^{1}$ & & \\
Employed & & \\
Unemployed & & \\
\hline
\end{tabular}

.58-.81) [57]. Adequate test-retest reliability has also been reported for the predecessor of the ADIS-IV, the ADISRevised [58], with kappas of.43 to.82.

Anxiety Disorders Interview Schedule, Parent version (ADIS-P) [42] The ADIS-P is a semi-structured interview designed to diagnose anxiety disorders in children and adolescents (through age 16 years). It is based on DSM-IV criteria and is used both to determine the diagnosis and its severity. The ADIS-P allows for differential diagnoses among all the DSM-IV anxiety and related disorders and provides data regarding symptomatology, etiology, and the course of the disorder [59]. The ADIS-P also provides information about the severity of any diagnoses using the same scale as the ADIS-IV. Silverman, Saavedra, and Pina [60] found excellent reliability for separation anxiety disorder, social phobia, specific phobia, and GAD as well as excellent test-retest reliability for the interview.

Semistructured diagnostic interviews have several advantages in comparison to questionnaires and rating scales. First, they provide specific diagnoses based on a diagnostic system such as the DSM. Thus, symptoms and behaviors are grouped into diagnostically meaningful clusters and onset, impairment, and other variables are taken into account. Second, the interviewer can ask additional questions or vary the wording of questions in order to be certain that the informant understands the question. Third, the interviewer can solicit examples of the behavior in question, ensuring the accuracy of the data.

The applicability of DSM-IV criteria to populations with DD has been widely discussed in the literature. Cooper,
Melville, and Einfeld [61] and Reiss, Levitan, and Szyszko [62] argue that reported prevalence rates of psychopathology may be an underestimate in populations with DD. Sovner and Hurley [63-66] suggested that although they may be less likely to be diagnosed, adults with DD have psychiatric disturbances that are conceptually the same as DSM disorders. Brown, Aman, and LeCavalier [67] argued that DSM-IV criteria are applicable to children and adolescents with mild or moderate intellectual disability. The IQs of $5.3 \%$ of the children with WS in the present study were in the range of severe intellectual disability, suggesting that the results may be a slight underestimate of the actual rates of anxiety disorders.

Differential Ability Scales (DAS) [68, 69] The DAS provides an assessment of general intellectual functioning. This measure was designed to provide specific information about an individual's strengths and weaknesses across a wide range of intellectual activities. The General Conceptual Ability (GCA; similar to IQ) is based on performance on the core subtests and has a mean of 100 and a standard deviation of 15 .

There are two levels of the DAS: Preschool and School Age. Following the test author's recommendation for children who are expected to have below average intelligence, the Preschool Level was administered to all children who were 6 years 11 months or younger. The School Age Level was administered to the remaining children unless they were very low functioning; these children completed the Preschool Level. If necessary, the GCA was calculated using the extended norms, which are available for the 
Preschool Level through age 13 years 11 months and for the School Age Level through age 17 years 11 months.

Scales of Independent Behavior-Revised (SIB-R) [70] The SIB-R provides an assessment of adaptive behavior. The parent interview form of the instrument was administered. It consists of 259 items; each item is scored on a 4-point Likert scale. The items are divided into four clusters: Motor Skills, Social Interaction and Communication, Personal Living Skills, and Community Living Skills. The Broad Independence standard score is based on parental responses to items in all four clusters. This standard score has a mean of 100 and a standard deviation of 15 . Additionally, the SIB-R assesses three domains of maladaptive behavior: Internalized, Asocial, and Externalized. The norms for the SIB-R extend from age 3 months to 90 years.

Child Behavior Checklist (CBCL) [71, 72] The CBCL is a Likert scale that provides an assessment of behavioral and emotional problems of children from parents and/or other caregivers. There are two versions of this instrument: one for children aged $11 / 2-5$ years and another for children aged 6-18 years. The Total Problems T score was used as a measure of behavioral problems in this study.

Training/reliability of student clinical interviewers

All interviewers who administered the ADIS-IV and ADIS-P had successfully completed reliability training for the interview. Training for the ADIS consisted of the following components: reviewing the interview, observing videotaped or live administrations of the interview, and assigning diagnoses and severity ratings for each interview. Interviewers were required to obtain three consecutive matches on diagnosis and its severity. Upon completion of this process, the interviewer administered a practice ADIS. This interview was videotaped and was rated by a licensed clinical psychologist. If the interviewer and the clinical psychologist diagnoses matched on principal and additional diagnoses as well as severity, the interviewer was permitted to administer the ADIS for the study. All interview protocols were reviewed with a licensed clinical psychologist. Disagreements were resolved by discussion.

\section{Results}

Prevalence rates of anxiety disorders in children with WS

Prevalence rates for each type of anxiety disorder in children with WS are shown in Table 3. Overall, 62.1\% of the children received a diagnosis of at least one anxiety disorder. The most prevalent anxiety disorder was specific phobia, found in $56.1 \%$ of the children. These prevalence rates were compared to those in the general population of children using a $z$-test, with the significance level set at.05. For this comparison, the findings of the Child and Adolescent Mental Disorders Study [3], the largest epidemiological study of psychiatric disorders in children in the USA using a reliable and valid structured diagnostic interview, the Diagnostic Interview Schedule for Children Version 2.3 (DISC-2.3) [3], were used (Table 3). We also compared these data to the prevalence rates of anxiety disorders in the largest epidemiological study of psychiatric disorders in children with DD [73], using the DISC-IV [74]. The children with WS had a significantly higher prevalence of specific phobia, GAD, and separation anxiety than did children either in the general population or an epidemiological sample of children with DD.

The prevalence rates of types of anxiety disorders were also compared between children with WS who had a sibling

Table 3 Prevalence of anxiety disorders in children with WS $(N=132)$, children in the general population, and children in the DD population

\begin{tabular}{|c|c|c|c|c|}
\hline \multirow[t]{2}{*}{ Type of anxiety disorder } & \multicolumn{2}{|c|}{ WS } & \multirow{2}{*}{$\frac{\text { Population prevalence }^{\mathrm{a}}}{\%}$} & \multirow{2}{*}{$\frac{\text { DD population prevalence }}{\mathrm{b}}$} \\
\hline & $N$ & $\%$ & & \\
\hline Separation anxiety disorder & 8 & 6.1 & $2.3 *$ & $1.9^{*}$ \\
\hline Social phobia & 3 & 2.3 & 4.5 & 1.9 \\
\hline GAD & 10 & 7.6 & $3.1^{*}$ & $0 * *$ \\
\hline OCD & 2 & 1.5 & $-^{\mathrm{c}}$ & 1.5 \\
\hline Specific phobia & 74 & 56.1 & $1.3 * *$ & $6.8^{* *}$ \\
\hline PTSD & 2 & 1.5 & $-^{\mathrm{c}}$ & $-^{\mathrm{c}}$ \\
\hline
\end{tabular}

$*_{p}<.01 ; * * p<.001$

${ }^{a}$ Prevalence established using the Diagnostic Interview Schedule for Children Version 2.3 (DISC-2.3), Parent version

${ }^{\mathrm{b}}$ Prevalence established using the DISC-IV, Parent version

${ }^{\mathrm{c}}$ Prevalence not reported. 
Table 4 Prevalence of anxiety disorders in mothers of children with WS $(N=132)$

\begin{tabular}{lrrc}
\hline Type of anxiety disorder & $N$ & $\%$ & $\begin{array}{c}\text { Population } \\
\text { Prevalence }(\%)^{\mathrm{a}}\end{array}$ \\
\hline Social phobia & 15 & 11.4 & 15.7 \\
GAD & 31 & 23.5 & $8.1^{* *}$ \\
OCD & 3 & 2.3 & 1.6 \\
Specific phobia & 27 & 20.5 & 17.9 \\
PTSD & 5 & 3.8 & $10.9^{*}$ \\
Panic disorder & 4 & 3.0 & 7.7 \\
\hline
\end{tabular}

${ }^{*} p<.01 ; * * p<.001$

${ }^{a}$ Prevalence assessed using the Composite International Diagnostic Interview

in the 4-16 year age range and those who did not. No significant difference was found in the prevalence of either anxiety disorders in general or specific anxiety disorders between the two groups.

Prevalence rates of anxiety disorders in mothers of children with WS

Lifetime prevalence of each type of anxiety disorder for the mothers participating in the study is reported in Table 4. The prevalence for each anxiety disorder was then compared to the prevalence in the general population of women in the same age range, using a $z$ test, with a significance level of $p<.05$. For population prevalence, the findings of the National Comorbidity Study Replication (NCS-R) were used [75; Table 4], adjusted to include the age range of the participants in the present study. The prevalence of GAD in the mothers of children with WS was significantly higher than in the general population of women.

To control for the influence of having a child with DD, the prevalence of GAD in the mothers prior to the birth of their child with WS was examined, taking into consideration the date of onset of GAD as reported by the mothers. This prevalence $(6.4 \%)$ was similar to that for the general population $(z=0.2, p=.827)$.

Table 5 Prevalence of anxiety disorders in children with WS and their siblings

\begin{tabular}{lrrrrr}
\hline Type of anxiety disorder & \multicolumn{2}{c}{$\mathrm{TD}(N=84)$} & & \multicolumn{2}{l}{ WS $(N=84)$} \\
\cline { 2 - 3 } \cline { 6 - 7 } & $N$ & & & $N$ & $\%$ \\
\hline Any anxiety disorder & 21 & 25.0 & & 51 & $60.7^{*}$ \\
Separation anxiety & 3 & 3.6 & & 3 & 3.6 \\
Social phobia & 6 & 7.1 & & 2 \\
GAD & 5 & 6.0 & & 9 & 10.7 \\
OCD & 0 & 0 & & 2 & 2.4 \\
Specific phobia & 14 & 16.7 & & 4 & $52.4^{*}$ \\
\hline
\end{tabular}

$* p<.001$
Prevalence rates of anxiety disorders in siblings of children with WS

Prevalence rates of each type of anxiety disorder in siblings of children with WS $(N=84)$ are reported in Table 5 . Overall, $25 \%$ of the siblings had a diagnosis of at least one anxiety disorder. The prevalence of each anxiety disorder and of any anxiety disorder was compared to the prevalence in the general population of children with typical development (TD), using a $z$ test, with a significance level of $p<.05$. For population prevalence, the findings of the Child and Adolescent Mental Disorders Study [3; Table 3] were used. The siblings of children with WS had a significantly higher prevalence of specific phobia $(p<.001)$ than Shaffer et al. reported for children in the general population.

The prevalence rates of anxiety disorders overall in children with WS were then compared to the prevalence in their TD siblings, using the McNemar test, a statistic used to test matched-pair data [76], with a significance level of $p<.05$. To control for environmental and genetic influences, only the subset of children with WS who had a sibling participating in the study $(N=84)$ was used for this analysis. (No difference was found in the prevalence of anxiety disorders between children with WS with and without siblings in the 4-16 year age range.) The children with WS had a significantly higher prevalence of anxiety disorders overall than their siblings $(p<.001)$. The children with WS also had a significantly higher prevalence of specific phobia than their siblings $(p<.001)$. Comparisons for the remaining categories of anxiety disorders were not performed because of the low expected frequencies for some of the cells. Note, however, that the prevalence of GAD for the children with WS was almost double that of their siblings and that the prevalence of social phobia for the children with WS was one-third that of their siblings.

\section{Predictors of anxiety in children with WS}

A logistic regression was conducted to determine the factors related to the presence of anxiety disorders in children with WS. The child's DAS GCA score, the age of the child with WS, the sex of the child with WS, and severity of maternal anxiety $(\mathrm{M}=1.6, \mathrm{SD}=2.2)$ were

Table 6 Logistic regression analysis summary for predictors of anxiety in children with WS

\begin{tabular}{lccc}
\hline Model & $B$ & SE & Odds ratio \\
\hline Age & .03 & .06 & 1.03 \\
Sex & -.58 & .42 & .56 \\
DAS GCA & -.02 & .02 & .98 \\
Severity of maternal anxiety & .42 & .12 & $1.52^{*}$ \\
\hline
\end{tabular}

$* p<.01$ 
Table 7 Logistic regression analysis summary for predictors of anxiety in mothers of children with WS

\begin{tabular}{lccc}
\hline Model & $B$ & SE & Odds ratio \\
\hline Age of the child with WS & .06 & .06 & 1.06 \\
DAS GCA & -.03 & .02 & $.96^{*}$ \\
Total problem behavior & .02 & .03 & 1.02 \\
Maternal employment & -.77 & .42 & $.46^{* *}$ \\
\hline
\end{tabular}

$* p<.05 ; * * p=.07$

entered as covariates (Table 6). The overall regression equation was significant, $\chi^{2}(4)=22.06, p<.001$. The model accounted for $22.0 \%$ of the variance in the anxiety in the child with WS. The odds of a child with WS having an anxiety disorder increased with the severity of maternal anxiety.

Predictors of anxiety in mothers of children with WS

A logistic regression analysis was conducted to determine the extent to which the age, IQ, overall behavioral problems of the child with WS, and maternal employment status predicted the presence of maternal anxiety. For this analysis, the mothers who reported the onset of their anxiety as occurring before having a child with WS were excluded $(n=14)$. The age of the child with WS, the child's DAS GCA, the child's CBCL Total Problems T score, and maternal employment status were entered as covariates (Table 7). The overall regression equation was significant, $\chi^{2}(4)=10.1, p=.039$, the model accounting for $12.0 \%$ of the variance of the presence of anxiety in mothers. The odds of the mother having an anxiety disorder increased significantly as the child's GCA decreased and marginally if the mother was employed outside of home.

\section{Predictors of anxiety in siblings of children with WS}

A logistic regression was conducted to test whether maternal anxiety, sibling age, and sibling sex predicted anxiety in the siblings. The overall regression equation was not significant, $\chi^{2}(3)=3.6, p=.312$, the model predicting only $7 \%$ of the variance. The prevalence rates of anxiety disorders overall in the siblings were then compared to the prevalence in their mothers, using the McNemar test, a statistic used to test matched-pair data [76], with a significance level of $p<.05$. For this analysis, we excluded the mothers who had the onset of anxiety after having a child with WS. No significant results were obtained $(p=.332)$. Spearman's rho was computed to investigate whether sibling anxiety correlated with the CA (-.14), severity of anxiety (.20), DAS GCA (-.11), SIB-R Broad Independence (-.05), or CBCL Total Problems T score (.10) of children with WS. None of these correlations was significant.

\section{Discussion}

The present study investigated the prevalence of anxiety disorders in children with WS, their mothers, and their siblings, using a DSM-IV-based semi-structured diagnostic interview with good psychometric properties. In addition, this study investigated potential predictors of anxiety in children with WS, their mothers, and their siblings. The results are discussed in the order of groups in the study: children with WS, their mothers, and their siblings. The final section focuses on the implications of these findings for the genetics of anxiety disorders.

\section{Children with WS}

The results of this study demonstrate that children with WS have elevated rates of anxiety disorders in comparison to children in the general population. When examined by type, children with WS have a significantly higher prevalence of specific phobia, GAD, and separation anxiety than children in the general population. The same pattern was found when the prevalence of anxiety disorders in children with WS was compared to that in an epidemiological sample of children with DD of mixed etiology [73].

These rates are also much higher than those previously reported for individuals with DD of other etiologies. Myers and Pueschel [77] reported phobias in only $1.5 \%$ of their sample of children and adolescents with Down syndrome. Backes et al. [78] reported separation anxiety in $10 \%$ and OCD in $2 \%$ of children with Fragile $\mathrm{X}$ syndrome. In a study of prevalence of psychiatric disorders in 264 children with DD of mixed etiology, Emerson [79] reported 1.9\% prevalence of specific phobia and $2.7 \%$ prevalence of separation anxiety. In the present study, the children with WS also had a significantly higher prevalence of specific phobia than their siblings. No comparisons with siblings were made for other anxiety disorders because of the low frequency in both groups.

The presence of maternal anxiety may further increase the rate of anxiety disorders in children with WS. Studies of children with TD have already demonstrated that the risk for anxiety disorders is higher for children of anxious parents than children of parents without anxiety [13-16]. However, children with WS have a much higher prevalence rate of anxiety disorder $(62.1 \%)$ than that reported for children of anxious parents (33\%) [80].

These findings overall demonstrate an elevated rate of anxiety disorders in children with WS, which per Karayiorgou and Gogos [25] is one of the two criteria demonstrating a causal relation between a chromosomal abnormality and a disease, in this case $7 q 11.23$ deletion and anxiety. It appears that the deletion increases the risk for developing an anxiety disorder in children with WS. The logistic regression results 
indicate that familial aggregation of anxiety may also contribute to the risk of developing an anxiety disorder in children with WS. This finding is consistent with results of family studies of anxiety disorders. An important focus for future research is to further investigate the separate and combined contributions of particular deleted gene(s) and history of maternal anxiety to anxiety in children with WS.

\section{Mothers of children with WS}

In this study, mothers of children with WS reported a significantly higher lifetime prevalence of GAD than women in the general population. Because no large studies have examined the prevalence of anxiety disorders in mothers of children with DD, no statistical comparisons were conducted with such populations. However, the mothers of children with WS also had a notably higher prevalence of anxiety disorders than mothers of children with Down syndrome or autism in previous studies, which have reported rates similar to or lower than those in the general population [47-48].

When the age of onset of GAD in the mothers was taken into account, it appeared that the prevalence rate for GAD for mothers of children with WS prior to the birth of the child with WS (as reported by the mothers in retrospect) was comparable to that for women in the general population, suggesting that maternal GAD may be at least in part related to the stress of raising a child with WS. One question is why mothers of children with WS have increased prevalence of GAD rather than of other types of anxiety disorders. It is possible that the diagnostic criteria for GAD (excessive worry or anxiety across a number of situations and events, which is difficult to control) [8] encompass the stressors directly associated with raising a child with WS, such as health, school, and behavior as well as stressors likely due to having a child with WS, but involving other family members, including spousal relations and parental relations with TD children. This finding is consistent with previous findings on the onset of GAD, demonstrating that later-onset GAD is associated with the emergence of life stressors [e.g., 81-83]. A potential limitation of this finding is that the onset of maternal GAD is based on a retrospective report by the mothers, and it is possible that the report is inaccurate and the mothers of children with WS have a higher prevalence of GAD than the women in the general population even prior to having the child with WS.

In the present study, child IQ significantly affected the odds of a mother having an anxiety disorder, suggesting that higher IQ was associated with decreased odds of the mother having an anxiety disorder. Additionally, mothers who were not employed outside of the home also had a marginally increased likelihood of having an anxiety disorder relative to mothers who were employed outside of the home. This difference was not due to lower family income; family income in families where the mothers were not employed was very similar to family income where the mothers were employed. This finding is consistent with that of Wittchen et al. [84], who found that in the National Comorbidity Survey being unemployed and being a homemaker were significantly correlated with the presence of GAD.

Overall, these findings suggest that the mothers of children with WS are at increased risk for developing an anxiety disorder later in life, which may be due to the environmental stress of raising a child with WS. It is possible that some of the mothers of children with WS may have a predisposition to developing an anxiety disorder which then becomes apparent in the presence of an environmental stressor. This is consistent with evidence from genetic studies. For example, in a study of 1,033 blindly assessed female-female twin pairs, Kendler et al. [85] estimated $30 \%$ heritability for GAD and postulated that the remainder of the variance may be accounted for by environmental factors.

Several steps may be taken to explore this issue further. First, studies are needed to compare the prevalence rates of anxiety disorders in mothers of children with WS with those of mothers of children with other types of DD. Second, larger studies examining potential environmental stressors in these mothers may also help clarify the relation between these stressors and the onset of anxiety. Examination of the interaction of the potential anxiety candidate genes and environmental influences and its effect on anxiety in this population will help explain the prevalence findings in the mothers and advance our knowledge of the etiology of anxiety disorders.

\section{Siblings of children with WS}

The siblings of children with WS had the same prevalence of anxiety disorders as children in the general population as measured by Shaffer et al. [3], with the exception of specific phobia. However, while the prevalence of specific phobia in siblings of children with WS was higher than that reported by Shaffer et al. [3], it was similar to the rates reported in other studies of specific phobia in children with TD [86, 87]. Lichtenstein and Annas [86] examined the prevalence of specific phobia in 1106 pairs of 8-9-year-old twins (both DZ and MZ), using a DSM-IV based questionnaire, and reported a rate of $8.6 \%$. Muris and Merckelbach [87] administered the specific phobia sections of the DISC-2.3 [3] to parents of 160 children aged 412 years and found a $17.6 \%$ prevalence of specific phobia. These findings suggest that the prevalence rate of specific phobia in the children in general population reported in 
Shaffer et al. [3] may be an underestimate. If so, the siblings of children with WS would not evidence increased prevalence of any anxiety disorder relative to children in the general population.

Neither history of maternal anxiety nor any factors related to the sibling with WS, such as IQ, behavior problems, or severity of anxiety disorder in the child with WS, predicted or correlated with the presence of anxiety disorder in the siblings. These results may be due to the small number of siblings who had an anxiety disorder. A study with a larger number of siblings of children with WS who have anxiety may be successful at identifying predictors of anxiety in the siblings. Additionally, comparison groups of siblings of children with DD and siblings of children from families in which all children are typically developing may help further clarify these findings.

Implications for genetic research on anxiety disorders

Research on complex disorders has demonstrated that examination of neurodevelopmental disorders of known genetic cause that are associated with high prevalence rates of a particular psychiatric disorder may be successful in identifying susceptibility genes for these disorders. Thus far this approach has not been applied to anxiety disorders. These and previous findings by Leyfer et al. [42] indicate that there may be a causal relation between anxiety and deletion of chromosome 7q11.23 [26]. It is thus possible that there is a susceptibility locus for anxiety on $7 \mathrm{q} 11.23$. This possibility can be further tested by means of genetic linkage and association studies. From this point on several strategies may be implemented to identify how 7q11.23 deletion may contribute to anxiety. For example, hemideletion of one or more genes in the WS region may cause increased anxiety. To test this possibility, association studies may be conducted on genes contained in the deleted region, using samples of TD individuals with and without an anxiety disorder.

It is also possible that the increased prevalence of anxiety in WS is due to the impact of the deletion of one or more genes in the deleted region on genes outside that region that are involved in anxiety. To test this possibility, association studies on anxiety can be conducted with individuals with WS targeting genes that have already been implicated in anxiety. Although the findings of association studies of anxiety disorders are conflicting thus far, several genes may be of potential interest. COMT, an enzyme responsible for the metabolism of noradrenaline and dopamine, encoded by a gene located on 22q11 [9] has been implicated in panic disorder [87] and OCD [88, 89]. Another gene that may be of potential interest is a variant of the serotonin transporter (SERT) gene, implicated in personality traits related to anxiety $[90,91]$. These genes can also be investigated in the mothers of children with WS.

When conducting association studies, several problems may arise. First, the selection of the control group will affect the results tremendously, because the differences between the two groups may not be related to genetics. For example, differences in allele frequencies may vary among different subgroups. To minimize such problems, Arnold et al. [10] suggest using family-based association methods. The mothers and siblings of children with WS can serve as the comparison group in future association studies. Future studies will need to focus on examining the prevalence of anxiety disorders in fathers of children with WS to determine the impact of paternal anxiety on anxiety in children with WS. It would also be useful to conduct large scale comparison studies of anxiety disorders and their predictors in children with WS, their siblings, and their parents and children with other types of $\mathrm{DD}$, their siblings, and their parents.

In conclusion, given the increased prevalence of anxiety disorders in children with WS, genetic studies examining possible links between particular genes deleted in WS and anxiety are warranted. It would also be worthwhile to investigate possible relations between genes deleted in WS and genes outside the deleted region that have been previously implicated in anxiety disorders in the general population. Research in this area likely will yield valuable new findings for determining the etiology of anxiety disorders in the general population.

Acknowledgments This research was supported by the following grants: R01 NS35102 from the National Institute of Neurological Disorders and Stroke (to C.B.M.) and R37 HD29957 from the National Institute of Child Health and Human Development (to C.B.M.).

We thank the children and their mothers for their enthusiastic participation in our research. Ella Peregrine, Angela John, and Melissa Rowe administered some of the intellectual assessments. Nicole Crawford, Angela Becerra, Colleen A. Morris, Julie Beasley, and Johanna Fricke administered some of the ADIS interviews. Doris Kistler provided statistical consultation. Joanie Robertson designed the database for this study and supervised data entry.

\section{References}

1. Kessler RC, McGonagle KA, Zhao S, Nelson CB, Hughes M, Eshleman S, et al. Lifetime and 12-month prevalence of DSM-III-R psychiatric disorders in the United States: results from the National Comorbidity Survey. Arch Gen Psychiatry 1994;51:8-19.

2. Ford T, Goodman R, Meltzer H. The British Child and Adolescent Mental Health Survey 1999: the prevalence of DSM-IV disorders. J Am Acad Child Adolesc Psychiatry 2003;42:1203-11.

3. Shaffer D, Fisher P, Dulcan MK, Davies M, Piacentini J, SchwabStone ME, et al. The NIMH Diagnostic Interview Schedule for Children Version 2.3 (DISC-2.3): Description, acceptability, prevalence rates, and performance in the MECA Study. Methods 
for the Epidemiology of Child and Adolescent Mental Disorders Study. J Am Acad Child Adolesc Psychiatry 1996;35:865-77.

4. Burke KC, Burke JD Jr, Regier DA, Rae DS. Age at onset of selected mental disorders in five community populations. Arch Gen Psychiatry 1990;47:511-8.

5. Kendall PC, Chansky TE, Kane MT, Kortlander E, Ronan K, Sessa FM, et al. Anxiety disorders in youth. Boston: Allyn and Bacon; 1993.

6. Belzer K, Schneier FR. Comorbidity of anxiety and depressive disorders: issues in conceptualization, assessment, and treatment. J Psychiatry Pract 2004;10:296-306.

7. Kessler RC, DuPont RL, Berglund P, Wittchen HU. Impairment in pure and comorbid generalized anxiety disorder and major depression at 12 months in two national surveys. Am J Psychiatry 1999; 156:1915-23.

8. American Psychiatric Association. Diagnostic and statistical manual of mental disorders, 4th Edition (DSM-IV). Washington, DC: American Psychiatric Association; 1994.

9. Woodman CL. The genetics of panic disorder and generalized anxiety disorder. Ann Clin Psychiatry 1993;5:231-9.

10. Arnold PD, Zai G, Richter MA. Genetics of anxiety disorders. Curr Psychiatry Rep 2004;6:243-54.

11. Crowe RR, Noyes R, Pauls DL, Slymen D. A family study of panic disorder. Arch Gen Psychiatry 1983;40:1065-9.

12. Noyes R Jr, Clarkson C, Crowe RR, Yates WR, McChesney CM. A family study of generalized anxiety disorder. Am J Psychiatry 1987;144:1019-24.

13. Nestadt G, Samuels J, Riddle M, Bienvenu OJ 3rd, Liang KY, LaBuda $M$, et al. A family study of obsessive-compulsive disorder. Arch Gen Psychiatry 2000;57:358-63.

14. Dierker LC, Merikangas KR, Szatmari P. Influence of parental concordance for psychiatric disorders on psychopathology in offspring. J Am Acad Child Adolesc Psychiatry 1999;38:280-8.

15. Merikangas KR, Avenevoli S, Dierker L, Grillon C. Vulnerability factors among children at risk for anxiety disorders. Biol Psychiatry 1999;46:1523-35.

16. Merikangas KR, Swendsen JD, Preisig MA, Chazan RZ. Psychopathology and temperament in parents and offspring: Results of a family study. J Affect Disord 1998;51:63-74.

17. Turner SM, Beidel DC, Costello A. Psychopathology in the offspring of anxiety disorders patients. J Consult Clin Psychol 1987;55:229-35.

18. Andrews G, Stewart G, Allen R, Henderson AS. The genetics of six neurotic disorders: a twin study. J Affect Disord 1999;19:23-9.

19. Hettema JM, Prescott CA, Kendler KS. A population-based twin study of generalized anxiety disorder in men and women. J Nerv Ment Dis 2001;189:413-20.

20. Kendler KS, Neale MC, Kessler RC, Heath AC, Eaves LJ. Panic disorder in women: a population-based twin study. Psychol Med 1993;23:397-406.

21. Torgersen S. Genetic factors in anxiety disorders. Arch Gen Psychiatry 1983;40:1085-9.

22. Hettema JM, Neale MC, Kendler KS. A review and meta-analysis of the genetic epidemiology of anxiety disorders. Am J Psychiatry 2001;158:1568-78.

23. Smoller JW, Finn C, White C. The genetics of anxiety disorders: An overview. Psychiatr Ann 2000;30:745-53.

24. Flint J. Behavioral phenotypes: conceptual and methodological issues. Am J Med Genet 1998;81:235-40.

25. Murphy KC. Schizophrenia and velo-cardio-facial syndrome. Lancet 2002;359:426-30.

26. Karayiorgou M, Gogos JA. A turning point in schizophrenia genetics. Neuron 19997;19:967-79.

27. Murphy KC, Owen MJ. Velo-cardio-facial syndrome: a model for understanding the genetics and pathogenesis of schizophrenia. $\mathrm{Br}$ J Psychiatry 2001;179:397-402.
28. Schupf N, Sergievsky GH. Genetic and host factors for dementia in Down's syndrome. Br J Psychiatry 2002;180:405-10.

29. Ewart AK, Morris CA, Atkinson D, Jin W, Sternes K, Spallone P, et al. Hemizygosity at the elastin locus in a developmental disorder. Williams syndrome. Nat Genet 1993;5:11-6.

30. Osborne LR. The molecular basis of a multisystem disorder. In: Morris CA, Lenhoff HM, Wang PP, editors. Williams-Beuren syndrome: Research, evaluation, and treatment. Baltimore: Johns Hopkins University Press; 2006. p. 18-58.

31. Morris CA. Williams syndrome. In: Cassidy SB, Allanson JE, editors. Management of genetic syndromes, 2nd ed. New York: Wiley; 2005. p. 655-67.

32. Mervis CB, Robinson BF, Bertrand J, Morris CA, Klein-Tasman BP, Armstrong SC. The Williams syndrome cognitive profile. Brain Cogn 2000;44:604-28.

33. Dykens EM. Anxiety, fears, and phobias in persons with Williams syndrome. Dev Neuropsychol 2003;23:291-316.

34. Einfeld S, Tonge B, Florio T. Behavioral and emotional disturbance in individuals with Williams syndrome. Am J Ment Retard 1997;102:45-53.

35. Einfeld S, Tonge B, Rees V. Longitudinal course of behavioral and emotional problems in Williams syndrome. Am J Ment Retard 2001;106:73-81.

36. Einfeld S, Tonge B, Turner G, Parmenter T, Smith A. Longitudinal course of behavioural and emotional problems of young persons with Prader-Willi, Fragile X, Williams and Down syndromes. J Intellect Dev Disabil 1999;24:349-54.

37. Gosch A, Pankau R. Personality characteristics and behaviour problems in individuals of different ages with Williams syndrome. Dev Med Child Neurol 1997;39:527-33.

38. Klein-Tasman BP, Mervis CB. Distinctive personality characteristics of 8-, 9-, and 10-year-olds with Williams syndrome. Dev Neuropsychol 2003;23:269-90.

39. Tonge B, Einfeld S. Psychopathology and intellectual disability: The Australian Child to Adult Longitudinal Study. In: Glidden LM, editor. International review of research in mental retardation. San Diego: Elsevier Science; 2003. p. 61-91.

40. Udwin O, Yule W. A cognitive and behavioural phenotype in Williams syndrome. J Clin Exp Neuropsychol 1991;13:232-44.

41. Udwin O, Yule W, Martin N. Cognitive abilities and behavioural characteristics of children with idiopathic infantile hypercalcaemia. J Child Psychol Psychiatry 1987;28:297-309.

42. Leyfer O, Woodruff-Borden J, Klein-Taskam BP, Fricke J, Mervis CB. Prevalence of psychiatric disorders in 4 to16-year-olds with Williams syndrome. Am J Med Gen 2006;B 141:615-22.

43. Silverman WK, Albano AM. The Anxiety disorders interview schedule for DSM-IV: Parent interview schedule. San Antonio: Graywind, a Division of the Psychological Corporation; 1996.

44. Harvey JM, O'Callaghan MJ, Vines B. Prevalence of maternal depression and its relationship to ADL skills in children with developmental delay. J Paediatr Child Health 1997;33:42-6.

45. Lenhard W, Breitenbach E, Ebert H, Schindelhauer-Deutscher HJ, Henn W. Psychological benefit of diagnostic certainty for mothers of children with disabilities: Lessons from Down syndrome. Am J Med Gen A 2005;133:170-5.

46. Piven J, Chase GA, Landa R, Wzorek M, Gayle J, Cloud D, et al. Psychiatric disorders in the parents of autistic individuals. J Am Acad Child Adolesc Psychiatry 1991;30:471-8.

47. Piven J, Palmer P. Psychiatric disorder and the broad autism phenotype: Evidence from a family study of multiple-incidence autism families. Am J Psychiatry 1999;156:557-63.

48. Spanbergerg JJ, Theron JC. Stress and coping in parents of children with Down syndrome. Studia Psychol 2001;43:41-8.

49. Weiss JA, Sullivan A, Diamond T. Parent stress and adaptive functioning of individuals with developmental disabilities. J Dev Disabil 2003;10:129-35. 
50. Emerson E. Mothers of children and adolescents with intellectual disability: Social and economic situation, mental health status, and the self-assessed social and psychological impact of the child's difficulties. J Intellect Disabil Res 2003;47:385-99.

51. Fidler DJ, Hodapp RM, Dykens EM. Behavioral phenotypes and special education: parent report of educational issues for children with Down syndrome, Prader-Willi syndrome, and Williams syndrome. J Spec Educ 2002;36:80-8.

52. Achenbach TM. Child behavior checklist/4-18. Burlington: University of Vermont; 1991.

53. McHale SM, Gamble WC. Sibling relationships with disabled and non-disabled brothers and sisters. Dev Psychol 1989;25:421-9.

54. Reynolds CR, Richmond BO. Revised Children's Manifest Anxiety Scale. Los Angeles: Western Psychological Services; 1985.

55. Coleby M. The school-aged siblings of children with disabilities. Dev Med Child Neurol 1995;37:415-26.

56. Brown TA, DiNardo PA, Barlow DH. Anxiety Disorders Interview Schedule, 4th ed. Boulder: Graywind; 1994.

57. Brown TA, DiNardo PA, Lehman CL, Campbell LA. Reliability of DSM-IV anxiety and mood disorders: Implications for the classification of emotional disorders. J Abnorm Psychol 2001;110:49-58.

58. Di Nardo P, Moras K, Barlow DH, Rapee RM, Brown TA. Reliability of DSM-III-R anxiety disorder categories. Using the Anxiety Disorders Interview Schedule-Revised (ADIS-R). Arch Gen Psychiatry 1993;50:251-6.

59. Silverman WK. Structured diagnostic interviews. In: Ollendick $\mathrm{TH}$, King NJ, Yule W, editors. International handbook of phobic and anxiety disorders in children and adolescents Issues in clinical child psychology. New York: Plenum; 1994. p. 293-315.

60. Silverman WK, Saavedra LM, Pina AA. Test-retest reliability of anxiety symptoms and diagnoses with the Anxiety disorders interview schedule for DSM-IV: Child and parent versions. J Am Acad Child Adolesc Psychiatry 2001;40:937-44.

61. Cooper SA, Melville CA, Einfeld SL. Psychiatric diagnosis, intellectual disabilities and diagnostic criteria for psychiatric disorders for use with adults with learning disabilities/mental retardation (DC-LD). J Intellect Dev Disabil Suppl 2003;1:3-15.

62. Reiss S, Levitan GW, Szyszko J. Emotional disturbance and mental retardation: Diagnostic overshadowing. Am J Ment Def 1982;86:567-74.

63. Sovner R. Limiting factors in the use of DSM-III criteria with mentally ill/mentally retarded persons. Psychopharmacol Bull 1986;22:1055-9.

64. Sovner R, Hurley AD. Do the mentally retarded suffer from affective illness? Arch Gen Psychiatry 1983;40:61-7.

65. Sovner R, Hurley AD. Diagnosing depression in the mentally retarded. Psych Aspects Ment Retard 1982;1:1-4.

66. Sovner R, Hurley AD. Diagnosing mania in the mentally retarded. Psych Aspects Ment Retard 1982;1:10-2.

67. Brown EC, Aman MG, Lecavalier L. Empirical classification of behavioral and psychiatric problems in children and adolescents with mental retardation. Am J Ment Retard 2004;109:445-55.

68. Elliott CD. Differential Ability Scales. San Antonio: The Psychological Corporation; 1990.

69. Elliott CD. Differential Ability Scales: Introductory and technical handbook. San Antonio: The Psychological Corporation; 1990.

70. Bruininks RH, Woodcock R, Weatherman R, Hill B. Scales of Independent Behavior - revised. Chicago: Riverside; 1996. p. 61.

71. Achenbach TM, Rescorla LA. Manual for ASEBA Preschool Forms and Profiles. Burlington: University of Vermont; 2001.

72. Achenbach TM, Rescorla LA. Manual for the ASEBA SchoolAge Forms and Profiles. Burlington: University of Vermont; 2001.
73. Dekker MC, Koot HM. DSM-IV disorders in children with borderline to moderate intellectual disability. I: Prevalence and impact. J Am Acad Child Adolesc Psychiatry 2003;42:914-22.

74. Shaffer D, Fisher P, Lucas C, Dulcan M, Schwab-Stone M. NIMH Diagnostic Interview Schedule for Children, Version IV (NIMH DISC-IV): description, differences from previous versions, and reliability of some common diagnoses. J Am Acad Child Adolesc Psychiatry 2000;39:28-38.

75. Kessler RC, Berglund P, Demler O, Jin R, Merikangas K, Walters EE. Lifetime prevalence and age of onset distributions of DSM-IV disorders in the National Comorbidity Survey Replication. Arch Gen Psychiatry 2005;62:593-602.

76. Sheskin DJ. Handbook of parametric and nonparametric statistical procedures, 2nd ed. Boca Raton: Chapman and Hall; 2000.

77. Myers BA, Pueschel SM. Psychiatric disorders in persons with Down syndrome. J Nerv Ment Dis 1991;179:609-13.

78. Backes M, Genc B, Schreck J, Doerfler W, Lehmkuhl G, von Gontard A. Cognitive and behavioral profile of fragile $\mathrm{X}$ boys: correlations to molecular data. Am J Med Genet 2000;95:150-6.

79. Emerson E. Prevalence of psychiatric disorders in children and adolescents with and without intellectual disability. J Intellect Disabil Res 2003;47:51-8.

80. Beidel DC, Turner SM. At risk for anxiety: I. Psychopathology in the offspring of anxious parents. J Am Acad Child Adolesc Psychiatry 1997;36:918-24.

81. Blazer D, Hughes D, George LK. Stressful life events and the onset of a generalized anxiety syndrome. Am J Psychiatry 1987; 144:1178-83.

82. Campbell LA, Brown TA, Grisham JR. The relevance of age of onset to the psychopathology of generalized anxiety disorder. Behavior Therapy 2003;34:31-48.

83. Hoehn-Saric R, Hazlett RL, McLeod DR. Generalized anxiety disorder with early and late onset of anxiety symptoms. Compr Psychiatry 1993;34:291-8.

84. Wittchen HU, Zhao S, Kessler RC, Eaves WW. DSM-III-R generalized anxiety disorder in $\backslash$ the National Comorbidity Survey. Arch Gen Psychiatry 1994;51:355-64.

85. Kendler KS, Neale MC, Kessler RC, Heath AC, Eaves LJ. Generalized anxiety disorder in women: a population-based twin study. Arch Gen Psychiatry 1992;49:267-72.

86. Lichtenstein P, Annas P. Heritability and prevalence of specific fears and phobias in childhood. J Child Psychol Psychiatry 2000;41:927-37.

87. Muris P, Merckelbach H. How serious are common childhood fears? II. The parent's point of view. Beh Res Therapy 2000;38:813-8.

88. Domschke K, Freitag CM, Kuhlenbaumer G, Schirmacher A, Sand P, Nyhuis P, et al. Association of the functional V158M catechol-O-methyl-transferase polymorphism with panic disorder in women. Int J Neuropsychop 2004;7:183-8.

89. Alsobrook JP, Zohar AH, Leboyer M, Chabane N, Ebstein RP, Pauls DL. Association between the COMT locus and obsessivecompulsive disorder in females but not males. Am J Med Genet 2000;114:116-20.

90. Lesch KP, Bengel D, Heils A, Sabol S, Greenberg B, Petri J, et al. Association of anxiety-related traits with a polymorphism in the serotonin transporter gene regulatory region. Science 1996;274: 1527-31.

91. Sen S, Burmeister M, Ghosh D. Meta-analysis of the association between a serotonin transporter promoter polymorphism (5HTTLPR) and anxiety-related personality traits. Am J Med Genet B 2004;127:85-9. 